\title{
Criterion-related validity of perceived exertion scales in healthy children: a systematic review and meta-analysis
}

\author{
Iván Rodríguez, Kinesiologist, ${ }^{a, b, c, d}$ Lysien Zambrano,M.D., ${ }^{\text {dee }}$ and Carlos Manterola,M.D. ${ }^{c, f, g}$
}

a. School of

Kinesiology, Faculty of Health Science,

San Sebastián

University,

Concepción, Chile.

b. School of

Kinesiology, Faculty of Health, Santo Tomás University, Concepción, Chile

c. Doctoral Program in Medical Sciences, Universidad de la Frontera, Temuco, Chile.

d. Doctoral Program in Pharmacology, Department of Physiology, Escola Paulista de Medicina, Universidade Federal de São Paulo, Brazil.

e. Department of Morphology, School of Medical Sciences, Universidad Nacional Autónoma de Honduras (UNAH), Honduras.

f. Department of Surgery, Universidad de La Frontera, Chile.

g. Biomedical Sciences Research Center, Universidad Autónoma de Chile.

E-mail address:

Iván Rodríguez, Kinesiologist: ivan. rodriguez@uss.cl

Funding:

None.

Conflict of interest: None.

Received: 06-30-2015 Accepted: 09-07-2015

\begin{abstract}
Introduction. Physiological parameters used to measure exercise intensity are oxygen uptake and heart rate. However, perceived exertion (PE) is a scale that has also been frequently applied. The objective of this study is to establish the criterionrelated validity of PE scales in children during an incremental exercise test.

Methods. Seven electronic databases were used. Studies aimed at assessing criterion-related validity of PE scales in healthy children during an incremental exercise test were included. Correlation coefficients were transformed into $\mathrm{z}$-values and assessed in a meta-analysis by means of a fixed effects model if $\mathrm{I}^{2}$ was below $50 \%$ or a random effects model, if it was above $50 \%$. Results. Twenty-five articles that studied 1418 children (boys: $49.2 \%$ ) met the inclusion criteria. Children's average age was 10.5 years old. Exercise modalities included bike, running and stepping exercises. The weighted correlation coefficient was 0.835 (95\% confidence interval: $0.762-0.887)$ and 0.874 (95\% confidence interval: 0.794-0.924) for heart rate and oxygen uptake as reference criteria. The production paradigm and scales that had not been adapted to children showed the lowest measurement performance $(p<0.05)$.

Conclusion. Measuring PE could be valid in healthy children during an incremental exercise test. Child-specific rating scales showed a better performance than those that had not been adapted to this population. Further studies with better methodological quality should be conducted in order to confirm these results.

Key words: validity, children, scales, cognition,
\end{abstract} exercise.

http:/ /dx.doi.org/10.5546/aap.2016.eng.120

\section{INTRODUCTION}

Physical exercise is important to maintain an adequate health status. An adequate method to assess exercise intensity helps to establish physiological thresholds that allow to stimulate exercise-induced adaptation mechanisms. ${ }^{1}$ Physiological outcome measures usually considered to assess and prescribe exercise are oxygen uptake $\left(\mathrm{VO}_{2}\right)$, heart rate (HR), blood lactate concentration, and respiratory rate (RR). ${ }^{1}$ However, given that measuring such outcomes requires costly equipment and expert supervision, perceived exertion (PE) has been frequently applied. ${ }^{2}$

PE can be considered as a configuration of symptoms: strain, aches and fatigue, involving the muscles and the cardiovascular and pulmonary systems during exercise.

As exercise intensity increases, there are corresponding and interdependent increases in response intensities along perceptual and physiological continua, demonstrating a strong positive correlation. ${ }^{2}$ Such association has allowed to use PE as an outcome measure, both to estimate workload and to produce a given level of intensity during exercise. For this reason, PE has become a clinically useful instrument, because it is a simple and cost-effective method that allows to establish and dose exercise intensity with a high degree of certainty. ${ }^{2,3}$

The Borg scale is one of the most commonly used PE rating scales and has demonstrated to be a valid tool in adult subjects. ${ }^{3}$ However, in children, this scale has not proven to have favorable psychometric properties. ${ }^{4-7}$ Accordingly, several linear scales have been developed for children on the basis of common expressions and a limited number range (0-10). All of these scales have been used with varying degrees of success as a means to measure PE. ${ }^{2}$ They have seemingly demonstrated adequate psychometric properties in children.

As per our knowledge, there are no studies aimed at establishing these scales' validity in children by means of meta-analyses. Therefore, the objectives of this study are to 
establish the criterion-related validity of PE rating scales in children, as well as to assess the impact of certain covariates associated with this measurement property.

\section{METHODS}

Design: Systematic review (SR). ${ }^{8}$

Article eligibility criteria: Studies conducted in humans, with a correlational design, and published in English, Portuguese, French or Spanish. Participants were defined as healthy male and female subjects younger than 18 years old. Studies that pooled data on adults or children with a concomitant pathology were excluded. Studies had to focus on establishing a correlation between PE and physiological outcome measures (reference criteria) during the incremental exercise test (IET). HR, $\mathrm{VO}_{2}$, workload, $\mathrm{RR}$, minute ventilation (VE), ventilatory equivalent ratio for oxygen $\left(\mathrm{VE} / \mathrm{VO}_{2}\right)$, and respiratory ratio $\left(\mathrm{VCO}_{2} / \mathrm{VO}_{2}\right)$ were defined as reference criteria.

Article search: Articles in the following databases were considered since their inclusion up to April 2015: Pubmed, ProQuest, Scientific Electronic Library Online (SciELO), SPORTDiscus, Rehabilitation and Sports Medicine Source (R\&SMS), Cumulative Index to Nursing \& Allied Health Literature (CINAHL), and Trip Database. Medical Subject Headings (MeSh) (children, adolescents, exercise, exercise test, dyspnea, cognition, heart rate, oxygen uptake, tidal volume, pulmonary ventilation, and respiratory rate) and free terms (perceived exertion, exercise intensity, validity, concurrent validity) were used. The Boolean operators AND and OR were also used. In addition, reference lists of primary articles were reviewed. The search took place between February and April 2015.

Article identification: Titles and abstracts from relevant articles were reviewed. Next, full texts corresponding to abstracts that met eligibility criteria and relevant articles from reference lists were obtained. Data were blindly collected by two independent investigators (IR and LZ) and recorded in a special worksheet. Year and language of publication, sample size, participants' age, exercise test, assessed PE rating scale, correlation coefficient (CC), and reference criteria were recorded.

Methodological quality and risk of bias assessment: Methodological quality (MQ) was assessed in an independent manner by two reviewers (IR and LZ) using the Consensus-based Standards for the Selection of Health Measurement Instruments
(COSMIN). The COSMIN scale allows to establish the methodological quality of studies aimed at assessing psychometric properties of health measurement parameters. Only the COSMIN section focused on assessing the methodological quality of criterion-related validity studies was considered for the purpose of this study. ${ }^{9}$

The risk of bias was assessed by establishing the correlation between CC and sample size. To this end, a funnel $\operatorname{plot}^{3,10}$ (Annex) was developed and the Kendall rank correlation coefficient was estimated (Begg and Mazumdar's rank correlation test).

Statistical analysis. When $\mathrm{VO}_{2}$ was reported both in absolute $(\mathrm{mL} / \mathrm{min})$ and relative $(\mathrm{mL} /$ $\mathrm{kg} / \mathrm{min}$ ) values in the same article, the weighted average CC was estimated (as per the sample size). Additionally, when the result of such association was presented as a coefficient of determination $\left(R_{2}\right)$, the square root was estimated to obtain Pearson's r CC.

A meta-analysis was done as per the HedgesOlkin's method, whereby CCs were tested using the Fisher z-transformation. ${ }^{3}$ In addition, inconsistency was estimated using $\mathrm{I}^{2}$ statistics as $\mathrm{I}^{2}=100 \%(\mathrm{Q}-\mathrm{DF}) / \mathrm{Q}$, where $\mathrm{Q}$ is Cochran's heterogeneity index and DF accounts for degrees of freedom. A value of $0 \%$ indicates lack of heterogeneity, any higher value indicates its presence. For analyses where $\mathrm{I}^{2}$ was below $50 \%$, a fixed effects model was used and, if $\mathrm{I}^{2}$ was above $50 \%$, a random effects model was applied. General criterion-related validity was established using the weighted correlation between PE and $\mathrm{HR}$, and between $\mathrm{PE}$ and $\mathrm{VO}_{2}$. The statistical analysis was done using the MedCalc Statistical Software v. 14.12.0 statistical package (MedCalc Software bvba, Ostend, Belgium), and a 95\% confidence interval (95\% CI) was considered statistically significant.

\section{RESULTS}

Study selection: The search obtained 3338 articles from the seven databases. Figure 1 describes the systematic search sequence and the reasons for exclusion. A total of 25 articles were considered for review (Figure 1).

Study characteristics: All articles were written in English. The year of publication ranged from 1986 to 2014. Sample size in these studies ranged between 283 and 14 participants; 1418 subjects completed the IET in the 25 studies, 699 (49.2\%) were boys, and 721 (50.8\%), girls. Average participant age was reported in 24 articles 
$(\mathrm{n}=1355,95.5 \%) ; 15(\mathrm{n}=923,65.0 \%)$ described age ranges. The weighted average age was 10.5 years old (maximum and minimum weighted average age: 13.1 and 9.7 years old). In addition, a continuous progressive exercise protocol was used in 21 articles $(n=1271,89.6 \%)$, while an intermittent progressive protocol was implemented in $4(\mathrm{n}=147,10.3 \%)$. Exercise modality was bike in 13 articles $(\mathrm{n}=831,58.6 \%)$, running in $9(\mathrm{n}=387,27.2 \%)$, and stepping test in 3 ( $\mathrm{n}=200,14.1 \%)$.

Besides, 23 articles assessed validity as per the estimation paradigm ( $\mathrm{n}=1332,93.9 \%)$ and 1 article used the production paradigm ( $\mathrm{n}=$ $70,4.9 \%)$. One article assessed both paradigms $(\mathrm{n}=16,1.1 \%)$.

In relation to the reference criterion used, 25 studies contemplated HR $(\mathrm{n}=1418,100 \%) ; 16$, $\mathrm{VO}^{2}(\mathrm{n}=732,51.6 \%) ; 7$, VE $(\mathrm{n}=297,20.9 \%) ; 7$, workload $(\mathrm{n}=302,21.2 \%)$; 4 , RR $(\mathrm{n}=218,15.3 \%)$;
3, $\mathrm{VCO}^{2} / \mathrm{VO}^{2}(\mathrm{n}=155,10.9 \%)$; and $2, \mathrm{VE} / \mathrm{VO}^{2}$ ( $\mathrm{n}=120,8.4 \%)$.

Lastly, 4 studies $(5,11-13)$ reported results on children with a concomitant disease and adults. However, only data regarding the population of interest were considered (Table 1).

Methodological quality and risk of bias: An intraclass CC $($ ICC) $>0.85$ was estimated among reviewers. For dissenting articles, decisions were made based on consensus. Thus, methodological quality was classified as "adequate" in 6 studies (24\%); "reasonable" in $9(36 \%)$; and "poor" in $10(40 \%)$. No study was classified as having an "excellent" methodological quality. In relation to the risk of bias, CCs were observed to have a symmetrical distribution in the funnel plot; there was no evident concentration of studies on any side of the weighted mean (Annex 1). In addition, a weak correlation between CCs and sample size

FIGURE 1. Flow chart

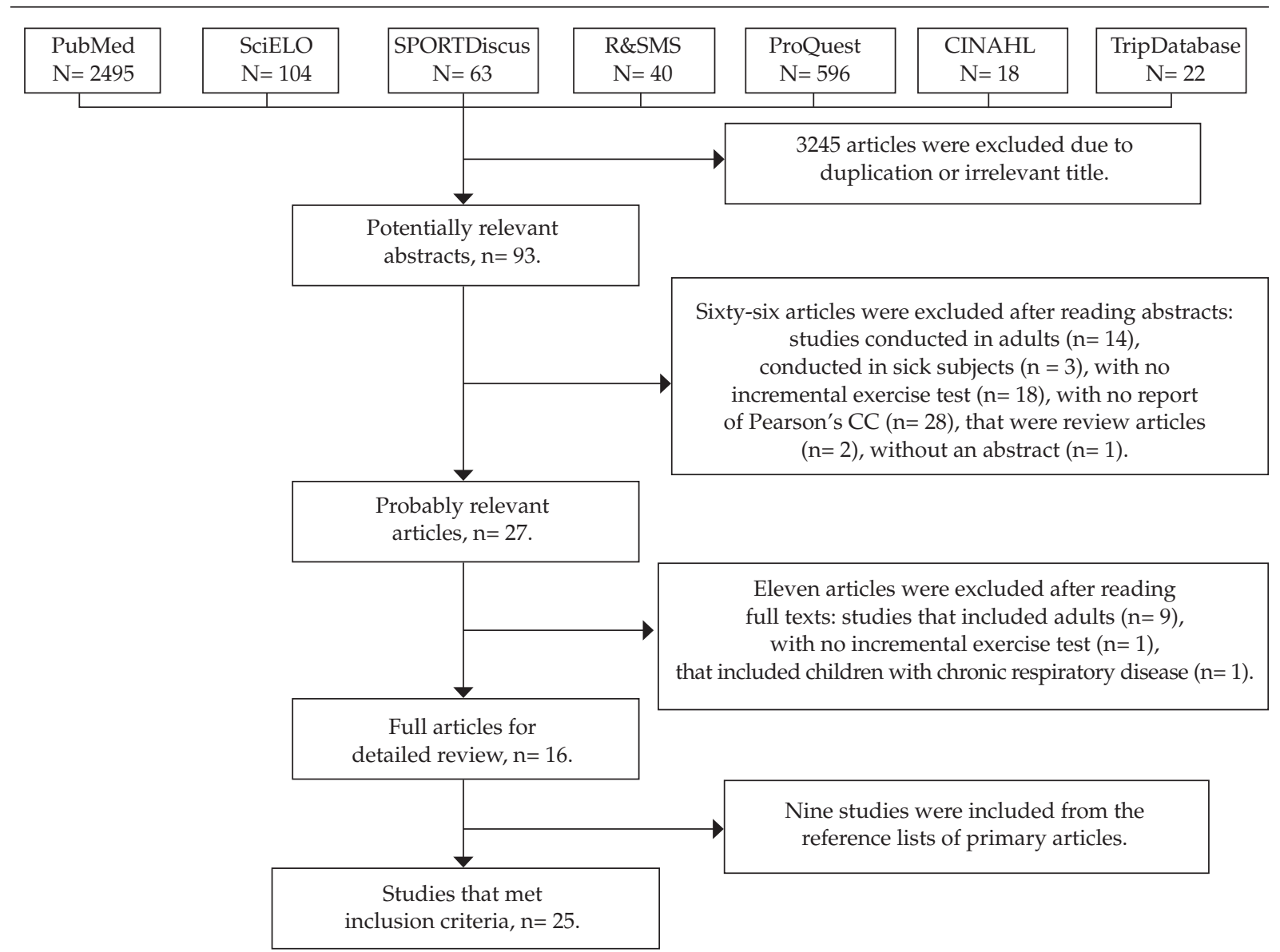

R\&SMS: Rehabilitation and Sports Medicine Source.

CC: correlation coefficient. 
( = $-0.148,95 \%$ CI: $-0.438-0.203)$ was observed. This suggests that studies had a low risk of bias.

Criterion-related validity of identified scales: Twelve assessment instruments were identified during the search: (1) 15-point Rate of Perceived Exertion (RPE 6-20) $(4-7,12,14,15)$; (2) Children's Effort Rating Table (CERT) (6, 7, 14, 16-18); children's OMNI scale of perceived exertion and its three variations: (3) OMNI-bike $(11,19$ 21), (4) OMNI-run $(15,22-25)$ and (5) OMNI-step (26); (6) 15-point Rate of Perceived ExertionChildren (RPE-C);13 (7) Pictorial Children's Effort Rating Table (PCERT);23,27,28 (8) Cart and Load Effort Rating (CALER) (20); (9) Children's Rating of Perceived Exertion Scale (C-RPES);29 (10) Borg ratings of perceived exertion scale (CR10) (27); (11) Eston-Parfitt curvilinear Ratings of Perceived Exertion (EP-RPE); ${ }^{30,31}$ (12) marble dropping task (MDT). ${ }^{30,31}$

The random effects model showed a weighted CC between PE and physiological outcome measures of 0.835 (95\% CI: 0.762-0.887) and 0.874 (95\% confidence interval: 0.794-0.924) considering $\mathrm{HR}$ and $\mathrm{VO}^{2}$ as reference criterion (Figures 2 and 3).

In addition, a specific meta-analysis was developed only for 7 of the 12 scales (RPE 6-20, CERT, OMNI-bike, OMNI-walk/run, PCERT, EP-RPE and MDT). The RPE 6-20 showed the lowest level of weighted correlation compared to the OMNI-bike and the EP-RPE (HR and $\left.\mathrm{VO}_{2}\right)$. Besides, the RPE 6-20 also showed the lowest weighted CC compared to the CERT and PCERT when considering only $\mathrm{HR}$ and $\mathrm{VO}_{2}$ as reference criterion, respectively. No significant difference was observed in any of the other analyzed scales. In turn, in relation to studies not subjected to meta-analysis, it was possible to verify that the RPE-C and CR-10 had the lowest weighted CCs and a significant difference from the CALER and C-RPES. Only the CR-10 evidenced a lower validity than the OMNI-step in relation to the $\mathrm{VO}_{2}$ criterion. In contrast, the C-RPES demonstrated a higher validity than the CERT in relation to the $\mathrm{VO}_{2}$ criterion (Table 2).

Table 3 shows criterion-related validity as per covariates. Significant differences were observed only in the assessment paradigm and other reference criteria. In this regard, both $\mathrm{VE} / \mathrm{VO}_{2}$ and the production paradigm showed a lower and statistically significant correlation. The rest of the covariates evidenced a moderate to high correlation, with no significant differences among their categories.

\section{DISCUSSION}

This study demonstrated that there is a strong overall correlation between PE and physiological outcome measures ( $\mathrm{HR}$ and $\mathrm{VO}_{2}$ ) during exercise. This suggests that measuring PE would be valid in children.

In relation to the specific analysis of identified scales, the RPE 6-20, RPE-C and CR10 evidenced the lowest correlation levels. It is worth noting that the RPE 6-20 and CR-10 were developed for the adult population, so they do not include intuitive, pictorial descriptors for children. ${ }^{4,5,12,14,15,27}$ Many studies have compared the Borg scale with pediatric scales, and it has been demonstrated that adapted scales have a better performance. ${ }^{6,14,15,27}$ For its part, the RPE-C is an adapted version of the Borg RPE 6-20 scale that includes pictures; however, it has demonstrated only a moderate correlation with physiological outcome measures during exercise. ${ }^{13}$ Although the RPE-C has not been compared to other instruments, it probably does not exceed the validity of other scales for children given its complex category range (6 to 20). Besides, higher CCs were observed for the OMNI scales (bike, walk/run and step), the EP-RPE, C-RPES, MDT, CALER and PCERT. Such scales include numerical, verbal and pictorial descriptors that are adequate for children, and this may account for their high validity..$^{11,15,19-24,26,29-34}$

In our study, and based on the covariate analysis, sex, age, exercise modality and protocol did not affect the validity of PE measurement. Our results are not consistent with the systematic review conducted by Chen, et al., who observed that some covariates may affect PE validity. ${ }^{3}$ However, Chen's study included adults, subjects with concomitant pathologies and other types of non-standardized exercise, and this may account for such differences.

Many lines of evidence indicate that there is a strong association between the stage of development and the ability to express PE in children. ${ }^{2,32,34}$ Recently, Rice, et al. observed that the validity of measuring PE increased proportionally with age. ${ }^{34}$ In our study, a lower correlation was observed in children younger than 7 years old when compared to children aged 13-15 years old; this suggests a possible association between cognitive development and the validity of PE measurement. The production modality also showed a lower validity level than the estimation modality $(p<0.05)$. However, only two primary studies that assessed this paradigm 
TABLE 1. Study characteristics

\begin{tabular}{|c|c|c|c|c|c|c|c|c|}
\hline Author & $\begin{array}{c}\text { Sample } \\
\text { size }(M / F)\end{array}$ & Age & $\begin{array}{l}\text { Exercise } \\
\text { protocol }\end{array}$ & $\begin{array}{l}\text { Exercise } \\
\text { modality }\end{array}$ & $\begin{array}{l}\text { Assessment } \\
\text { paradigm }\end{array}$ & $\begin{array}{l}\text { PE } \\
\text { scale }\end{array}$ & $\begin{array}{l}\text { Physiological } \\
\text { criterion }\end{array}$ & $\begin{array}{l}\text { Methodological } \\
\text { quality }\end{array}$ \\
\hline $\begin{array}{l}\text { Eston et al., } \\
1986\end{array}$ & $\begin{array}{c}30 \\
(30 / 0)\end{array}$ & 16.0 & $\begin{array}{l}\text { Continuous } \\
\text { progressive }\end{array}$ & Bike & Estimation & RPE 6-20 & HR, load & Reasonable \\
\hline $\begin{array}{l}\text { Gillach et al., } \\
1989\end{array}$ & $\begin{array}{c}283 \\
(144 / 139)\end{array}$ & 11.0 & $\begin{array}{l}\text { Continuous } \\
\text { progressive }\end{array}$ & Bike & Estimation & RPE 6-20 & HR & Reasonable \\
\hline $\begin{array}{l}\text { Eakin et al., } \\
1992\end{array}$ & $15(7 / 8)$ & 13.3 & $\begin{array}{l}\text { Continuous } \\
\text { progressive }\end{array}$ & Run & Estimation & RPE 6-20 & $\mathrm{HR}, \mathrm{VO}_{2}$ & Poor \\
\hline $\begin{array}{l}\text { William et al., } \\
1994\end{array}$ & $\begin{array}{c}112 \\
(56 / 56)\end{array}$ & 7.1 & $\begin{array}{l}\text { Continuous } \\
\text { progressive }\end{array}$ & Step & Estimation & CERT & HR & Reasonable \\
\hline $\begin{array}{l}\text { Eston et al., } \\
1994\end{array}$ & $\begin{array}{c}16 \\
(8 / 8)\end{array}$ & 10.0 & $\begin{array}{l}\text { Continuous } \\
\text { progressive }\end{array}$ & Bike & $\begin{array}{c}\text { Estimation and } \\
\text { production }\end{array}$ & CERT & HR, load & Poor \\
\hline $\begin{array}{l}\text { Lamb, } \\
1995\end{array}$ & $\begin{array}{c}70 \\
(28 / 42)\end{array}$ & 9.5 & $\begin{array}{l}\text { Continuous } \\
\text { progressive }\end{array}$ & Bike & Estimation & $\begin{array}{l}\text { RPE 6-20, } \\
\text { CERT }\end{array}$ & HR, load & Reasonable \\
\hline $\begin{array}{l}\text { Lamb, } \\
1996\end{array}$ & $\begin{array}{c}70 \\
(28 / 42)\end{array}$ & 9.5 & $\begin{array}{l}\text { Intermittent } \\
\text { progressive }\end{array}$ & Bike & Production & $\begin{array}{l}\text { RPE 6-20, } \\
\text { CERT }\end{array}$ & HR, load & Reasonable \\
\hline $\begin{array}{l}\text { Cassady et al., } \\
1998\end{array}$ & $\begin{array}{c}30 \\
(17 / 13)\end{array}$ & 9.6 & $\begin{array}{l}\text { Continuous } \\
\text { progressive }\end{array}$ & Bike & Estimation & C-RPES & $\begin{array}{l}\mathrm{HR}, \mathrm{VO}_{2}, \mathrm{RR}, \\
\mathrm{VE}, \mathrm{VCO}_{2} / \mathrm{VO}_{2}\end{array}$ & Reasonable \\
\hline $\begin{array}{l}\text { Robertson } \\
\text { et al., } 2000\end{array}$ & $\begin{array}{c}80 \\
(40 / 40)\end{array}$ & 10.0 & $\begin{array}{l}\text { Continuous } \\
\text { progressive }\end{array}$ & Bike & Estimation & $\begin{array}{l}\text { OMNI- } \\
\text { Bike }\end{array}$ & $\mathrm{HR}, \mathrm{VO}_{2}$ & Adequate \\
\hline $\begin{array}{l}\text { Groslambert } \\
\text { et al., } 2001\end{array}$ & $\begin{array}{c}25 \\
(13 / 12)\end{array}$ & 9.8 & $\begin{array}{l}\text { Continuous } \\
\text { progressive }\end{array}$ & Run & Estimation & RPE-C & HR & Reasonable \\
\hline $\begin{array}{l}\text { Utter et al., } \\
2002\end{array}$ & $\begin{array}{c}63 \\
(32 / 31)\end{array}$ & $13-6^{*}$ & $\begin{array}{l}\text { Continuous } \\
\text { progressive }\end{array}$ & Run & Estimation & $\begin{array}{l}\text { OMNI- } \\
\text { walk/run }\end{array}$ & $\begin{array}{l}\mathrm{HR}, \mathrm{VO}_{2}, \mathrm{RR}, \\
\mathrm{VE}, \mathrm{VE} / \mathrm{VO}_{2}\end{array}$ & Reasonable \\
\hline $\begin{array}{l}\text { Pfeiffer } \\
\text { et al., } 2002\end{array}$ & $\begin{array}{c}57 \\
(0 / 57)\end{array}$ & 15.3 & $\begin{array}{l}\text { Continuous } \\
\text { progressive }\end{array}$ & Run & Estimation & $\begin{array}{c}\text { RPE 6-20, } \\
\text { OMNI- } \\
\text { walk/run }\end{array}$ & $\begin{array}{l}\mathrm{HR}, \mathrm{VO}_{2^{\prime}} \mathrm{RR}, \\
\mathrm{VE}, \mathrm{VE} / \mathrm{VO}_{2} \\
\mathrm{VCO}_{2} / \mathrm{VO}_{2}\end{array}$ & Adequate \\
\hline $\begin{array}{l}\text { Yelling } \\
\text { et al., } 2002\end{array}$ & $\begin{array}{c}48 \\
(24 / 24)\end{array}$ & 13.8 & $\begin{array}{l}\text { Intermittent } \\
\text { progressive }\end{array}$ & Step & Estimation & PCERT & HR & Reasonable \\
\hline $\begin{array}{l}\text { Leung et al., } \\
2002\end{array}$ & $\begin{array}{c}69 \\
(34 / 35)\end{array}$ & 10.3 & $\begin{array}{l}\text { Continuous } \\
\text { progressive }\end{array}$ & Bike & Estimation & $\begin{array}{l}\text { RPE 6-20, } \\
\text { CERT }\end{array}$ & $\begin{array}{l}\mathrm{HR}, \mathrm{VO}_{2^{\prime}} \\
\text { load }\end{array}$ & Adequate \\
\hline $\begin{array}{l}\text { Robertson } \\
\text { et al., } 2005\end{array}$ & $\begin{array}{c}40 \\
(20 / 20)\end{array}$ & 11.1 & $\begin{array}{l}\text { Continuous } \\
\text { progressive }\end{array}$ & Step & Estimation & $\begin{array}{l}\text { OMNI- } \\
\text { step }\end{array}$ & $\mathrm{HR}, \mathrm{VO}_{2}$ & Reasonable \\
\hline $\begin{array}{l}\text { Rommeich } \\
\text { et al., } 2006\end{array}$ & $\begin{array}{c}51 \\
(26 / 25)\end{array}$ & 11.2 & $\begin{array}{l}\text { Continuous } \\
\text { progressive }\end{array}$ & Run & Estimation & $\begin{array}{l}\text { OMNI-walk/ } \\
\text { run PCERT }\end{array}$ & $\begin{array}{l}\mathrm{HR} \\
\mathrm{VO}_{2}\end{array}$ & Adequate \\
\hline $\begin{array}{l}\text { Robertson } \\
\text { et al., } 2006\end{array}$ & $\begin{array}{c}44 \\
(22 / 22)\end{array}$ & 12.8 & $\begin{array}{l}\text { Continuous } \\
\text { progressive }\end{array}$ & Run & Estimation & $\begin{array}{c}\text { OMNI- } \\
\text { walk/run }\end{array}$ & $\begin{array}{l}\mathrm{HR}, \\
\mathrm{VO}_{2}\end{array}$ & Reasonable \\
\hline $\begin{array}{l}\text { Barkley et al., } \\
2008\end{array}$ & $\begin{array}{c}32 \\
(16 / 16)\end{array}$ & 9.5 & $\begin{array}{l}\text { Continuous } \\
\text { progressive }\end{array}$ & Bike & Estimation & $\begin{array}{l}\text { OMNI-Bike, } \\
\text { CALER }\end{array}$ & $\mathrm{HR}, \mathrm{VO}_{2}$ & Reasonable \\
\hline $\begin{array}{l}\text { Marinov } \\
\text { et al., } 2008\end{array}$ & $\begin{array}{c}50 \\
(25 / 25)\end{array}$ & 10.4 & $\begin{array}{l}\text { Continuous } \\
\text { progressive }\end{array}$ & Run & Estimation & $\begin{array}{l}\text { CR-10, } \\
\text { PCERT }\end{array}$ & $\begin{array}{l}\mathrm{HR}, \mathrm{VO}_{2^{\prime}} \\
\quad \mathrm{VE}\end{array}$ & Reasonable \\
\hline $\begin{array}{l}\text { Suminski } \\
\text { et al., } 2008\end{array}$ & $\begin{array}{c}68 \\
(32 / 36)\end{array}$ & 10.2 & $\begin{array}{l}\text { Continuous } \\
\text { progressive }\end{array}$ & Run & Estimation & $\begin{array}{c}\text { OMNI- } \\
\text { walk/run }\end{array}$ & $\begin{array}{l}\mathrm{HR}, \mathrm{VO}_{2^{\prime}} \mathrm{RR}, \\
\mathrm{VCO}_{2} / \mathrm{VO}_{2^{\prime}}, \mathrm{VE}\end{array}$ & E Adequate \\
\hline $\begin{array}{l}\text { Leung et al., } \\
2008\end{array}$ & $\begin{array}{c}32 \\
(17 / 15)\end{array}$ & 10.5 & $\begin{array}{l}\text { Continuous } \\
\text { progressive }\end{array}$ & Bike & Estimation & CERT & HR, load & Reasonable \\
\hline $\begin{array}{l}\text { Eston et al., } \\
2009\end{array}$ & $\begin{array}{c}15 \\
(6 / 9)\end{array}$ & 7.6 & $\begin{array}{l}\text { Intermittent } \\
\text { progressive }\end{array}$ & Bike & Estimation & $\begin{array}{c}\text { EP-RPE, } \\
\text { MDT }\end{array}$ & $\begin{array}{l}\mathrm{HR}, \mathrm{VO}_{2^{\prime}} \\
\text { load, } \mathrm{VE}^{-}\end{array}$ & Poor \\
\hline $\begin{array}{l}\text { Lambrick } \\
\text { et al., } 2011\end{array}$ & $\begin{array}{c}14 \\
(8 / 6)\end{array}$ & 7.9 & $\begin{array}{l}\text { Intermittent } \\
\text { progressive }\end{array}$ & Run & Estimation & $\begin{array}{c}\text { EP-RPE, } \\
\text { MDT }\end{array}$ & $\begin{array}{l}\mathrm{HR}, \mathrm{VO}_{2^{\prime}} \\
\mathrm{VE}\end{array}$ & Poor \\
\hline $\begin{array}{l}\text { Balasekaran } \\
\text { et al., } 2012\end{array}$ & $\begin{array}{c}81 \\
(45 / 36)\end{array}$ & 13.8 & $\begin{array}{l}\text { Continuous } \\
\text { progressive }\end{array}$ & Bike & Estimation & $\begin{array}{l}\text { OMNI- } \\
\text { Bike }\end{array}$ & $\mathrm{HR}, \mathrm{VO}_{2}$ & Adequate \\
\hline $\begin{array}{l}\text { Balasekaran } \\
\text { et al., } 2014\end{array}$ & $\begin{array}{c}23 \\
(23 / 0)\end{array}$ & 13.8 & $\begin{array}{l}\text { Continuous } \\
\text { progressive }\end{array}$ & Bike & Estimation & $\begin{array}{l}\text { OMNI- } \\
\text { Bike }\end{array}$ & $\mathrm{HR}, \mathrm{VO}_{2}$ & Poor \\
\hline
\end{tabular}

* Only a range is reported; PE: perceived exertion; 15-point Rate of Perceived Exertion (RPE 6-20); Children's Effort Rating Table (CERT); children's OMNI scale of perceived exertion; 15-point Rate of Perceived Exertion-Children (RPE-C); Pictorial Children's Effort Rating Table (PCERT); Cart and Load Effort Rating (CALER); Children's Rating of Perceived Exertion Scale (C-RPES); Borg ratings of perceived exertion scale (CR-10); Eston-Parfitt curvilinear Ratings of Perceived Exertion (EP-RPE); marble dropping task (MDT);HR: heart rate; $\mathrm{VO}_{2}$ : oxygen uptake; RR: respiratory rate; VE: minute ventilation; $\mathrm{VCO}_{2} / \mathrm{VO}_{2}$ : respiratory ratio; $\mathrm{VE} / \mathrm{VO}_{2}$ : ventilatory equivalent ratio for oxygen. 
FIGURE 2. Meta-analysis of studies that consider heart rate as a reference criterion

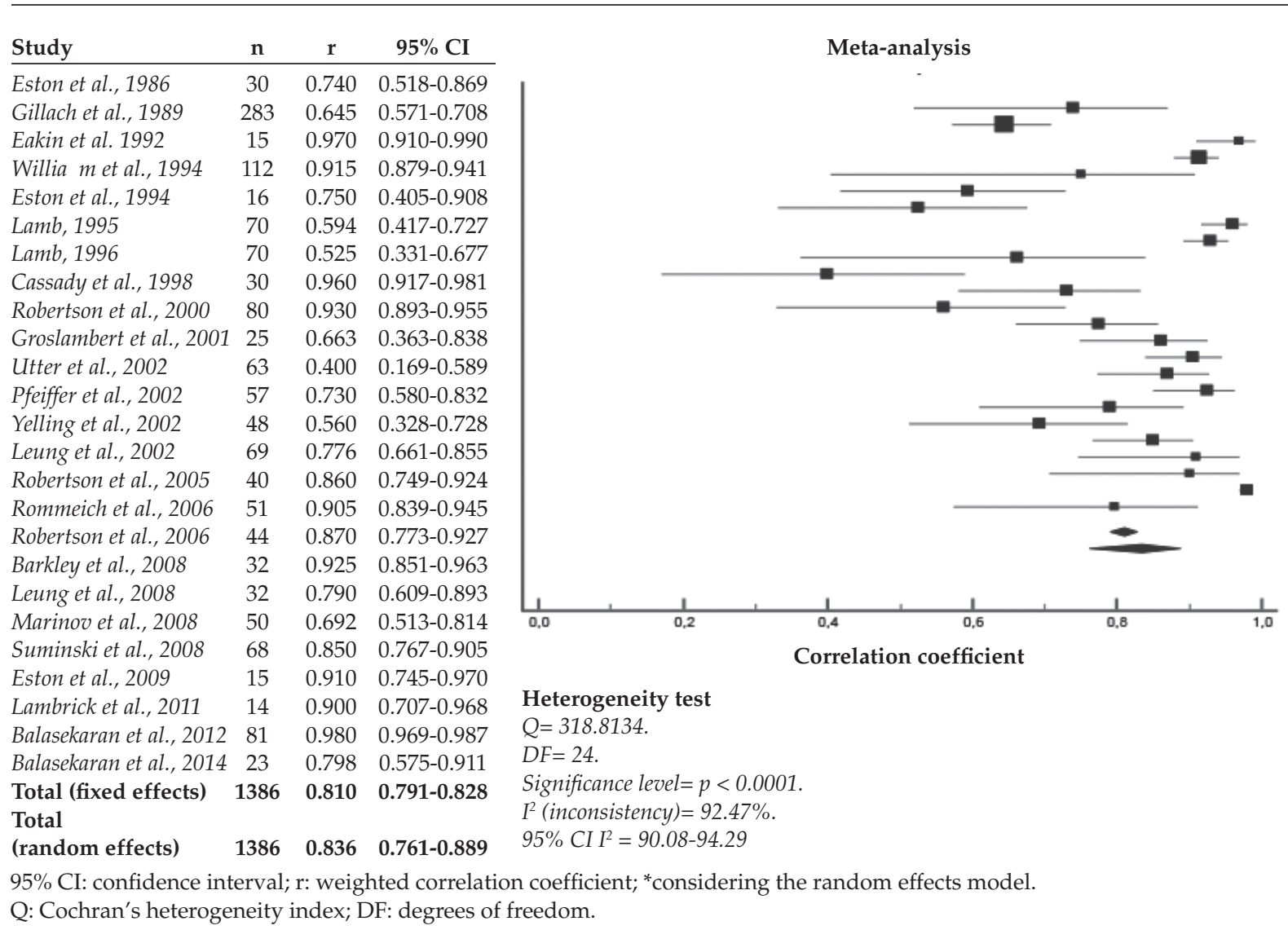

FIGURE 3. Meta-analysis of studies that consider oxygen uptake as a reference criterion

\begin{tabular}{lccc} 
Study & $\mathbf{n}$ & $\mathbf{r}$ & $\mathbf{9 5 \%} \mathbf{C I}$ \\
\hline Eakin et al., 1992 & 15 & 0.850 & $0.598-0.949$ \\
Cassady et al., 1998 & 30 & 0.970 & $0.937-0.986$ \\
Robertson et al., 2000 & 80 & 0.940 & $0.908-0.961$ \\
Utter et al., 2002 & 63 & 0.370 & $0.135-0.566$ \\
Pfeiffer et al., 2002 & 57 & 0.765 & $0.630-0.855$ \\
Leung et al., 2002 & 69 & 0.780 & $0.666-0.858$ \\
Robertson et al., 2005 & 40 & 0.910 & $0.835-0.952$ \\
Rommeich et al., 2006 & 51 & 0.910 & $0.847-0.948$ \\
Robertson et al., 2006 & 44 & 0.870 & $0.773-0.927$ \\
Barkley et al., 2008 & 32 & 0.885 & $0.776-0.943$ \\
Marinov et al., 2008 & 50 & 0.766 & $0.621-0.861$ \\
Suminski et al., 2008 & 68 & 0.800 & $0.694-0.872$ \\
Eston et al., 2009 & 15 & 0.900 & $0.719-0.967$ \\
Lambrick et al., 2011 & 14 & 0.895 & $0.694-0.967$ \\
Balasekaran et al., 2012 & 81 & 0.980 & $0.969-0.987$ \\
Balasekaran et al., 2014 & 23 & 0.740 & $0.858-0.892$ \\
Total (fixed effects) & $\mathbf{7 3 2}$ & $\mathbf{0 . 8 7 6}$ & $\mathbf{0 . 8 5 7 - 0 . 8 9 2}$ \\
Total (random effects) & $\mathbf{7 3 2}$ & $\mathbf{0 . 8 7 4}$ & $\mathbf{0 . 7 9 4 - 0 . 9 2 4}$
\end{tabular}

Q: Cochran's heterogeneity index;

DF: degrees of freedom.

\section{Heterogeneity test}

$\mathrm{Q}=180.2103$

$D F=15$.

Significance level $=p<0.0001$

$I^{2}($ inconsistency $)=91.68 \%$.

$95 \%$ CI I $I^{2}=88.09-94.18$

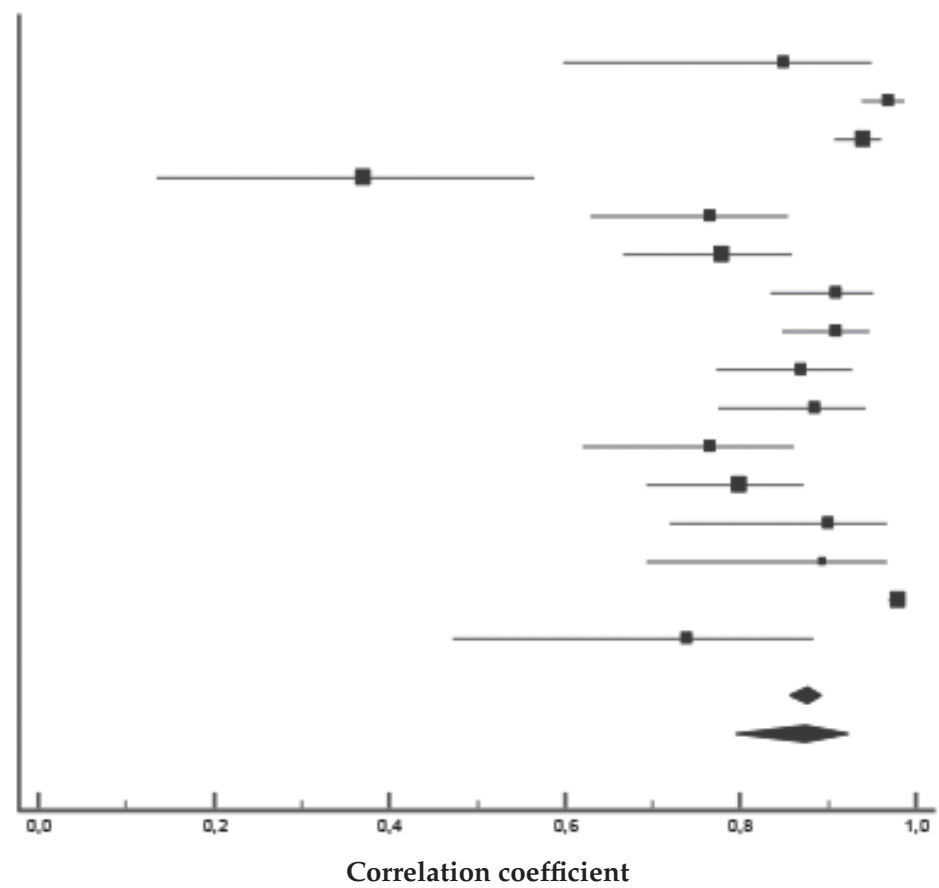

95\% CI: confidence interval; r: weighted correlation coefficient; ${ }^{*}$ considering the random effects model. 
by establishing a correlation between PE and physiological parameters were identified..$^{4,7}$ Studies using different statistical approaches, such as an analysis of variance (ANOVA) were excluded from the systematic review because they have shown inconsistent results, ${ }^{33,35}$ probably due to the complex psychophysical process required to produce exercise intensity based on PE. ${ }^{2}$ Further studies are necessary to verify all such hypotheses.

When analyzing reference criteria, and except for $\mathrm{VE} / \mathrm{VO}_{2}$ (Table 3), outcome measures could also work as useful criteria to establish criterionrelated validity of $\mathrm{PE}$, just like $\mathrm{HR}$ and $\mathrm{VO}_{2}$.

One of the limitations of this systematic review is that the methodological quality of 18 studies $(75 \%)$ was "reasonable" or "poor". The main reasons for this are associated with weaknesses in methodological design and a small sample size, which affect the statistical power of results. A high level of heterogeneity was also observed, probably due to methodological differences among studies. In this context, differences in sample size, incremental protocol design, duration and number of intensity intervals, and methodology used to measure PE were observed in primary studies. This may have contributed to the high levels of heterogeneity observed here.

Given the high external validity of this research design, results allow to support the use of PE to monitor intensity during exercise in subjects younger than 18 years old. Nevertheless, it is still necessary to verify its psychometric properties in children with concomitant pathologies and using other exercise modalities.

Lastly, this study's results suggest that measuring PE would be valid in healthy children during an incremental exercise test. In addition,

Table 2. Criterion-related validity of identified scales

\begin{tabular}{|c|c|c|c|c|c|c|c|c|}
\hline Scale & Criterion & Average $r$ & $\mathbf{k}$ & $\mathbf{n}$ & $95 \% \mathrm{CI}$ & $p$ & $\mathrm{Q}$ & $\mathrm{I}^{2}(p$-value $)$ \\
\hline \multirow[t]{2}{*}{ RPE (6-20) } & HR & $0.697^{\mathrm{a}}$ & 7 & 523 & $0.649-0.739$ & $<0.001$ & 11.3393 & $47.09 \%(0.0078)$ \\
\hline & $\mathrm{VO}_{2}$ & $0.695^{\mathrm{a}}$ & 3 & 106 & $0.578-0.785$ & $<0.001$ & 2.2748 & $12.08 \%(0.3207)$ \\
\hline \multirow[t]{2}{*}{ CERT } & $\mathrm{HR}$ & $0.778^{\mathrm{b}}$ & 6 & 301 & $0.572-0.892$ & $<0.001$ & 49.1602 & $89.83 \%(<0.0001)$ \\
\hline & $\mathrm{VO}_{2}$ & 0.870 & 1 & 35 & $0.756-0.933$ & NA & NA & NA \\
\hline \multirow[t]{2}{*}{ OMNI-bike } & $\mathrm{HR}$ & $0.935^{\mathrm{b}}$ & 4 & 216 & $0.843-0.974$ & $<0.001$ & 30.9730 & $90.31 \%(<0.0001)$ \\
\hline & $\mathrm{VO}_{2}$ & $0.926^{\mathrm{b}}$ & 4 & 216 & $0.804-0.973$ & $<0.001$ & 38.0031 & $91.11 \%(<0.0001)$ \\
\hline \multirow[t]{2}{*}{ OMNI-walk/run } & $\mathrm{HR}$ & $0.806^{\mathrm{b}}$ & 5 & 283 & $0.637-0.901$ & 0.001 & 36.3875 & $89.01 \%(<0.0001)$ \\
\hline & $\mathrm{VO}_{2}$ & $0.819^{b}$ & 5 & 283 & $0.627-0.917$ & $<0.001$ & 48.0952 & $91.68 \%(<0.0001)$ \\
\hline \multirow[t]{2}{*}{ OMNI-step } & $\mathrm{HR}$ & 0.860 & 1 & 40 & $0.749-0.924$ & NA & NA & NA \\
\hline & $\mathrm{VO}_{2}$ & 0.910 & 1 & 40 & $0.835-0.952$ & NA & NA & NA \\
\hline \multirow[t]{2}{*}{ RPE-C } & $\mathrm{HR}$ & 0.663 & 1 & 25 & $0.363-0.838$ & NA & NA & NA \\
\hline & $\mathrm{VO}_{2}$ & - & - & - & - & - & - & - \\
\hline \multirow[t]{2}{*}{ PCERT } & $\mathrm{HR}$ & $0.769^{b}$ & 3 & 149 & $0.482-0.907$ & $<0.001$ & 17.6863 & $88.69 \%(0.0001)$ \\
\hline & $\mathrm{VO}_{2}$ & $0.861^{a}$ & 2 & 101 & 0.798-0.904 & $<0.001$ & 1.5549 & $35.69 \%(0.2124)$ \\
\hline \multirow[t]{2}{*}{ CALER } & $\mathrm{HR}$ & 0.920 & 1 & 32 & $0.841-0.961$ & NA & NA & NA \\
\hline & $\mathrm{VO}_{2}$ & 0.880 & 1 & 32 & $0.767-0.940$ & NA & NA & NA \\
\hline \multirow[t]{2}{*}{ C-RPES } & $\mathrm{HR}$ & 0.960 & 1 & 30 & $0.917-0.981$ & NA & NA & NA \\
\hline & $\mathrm{VO}_{2}$ & 0.970 & 1 & 30 & $0.937-0.986$ & NA & NA & NA \\
\hline \multirow[t]{2}{*}{ CR-10 } & HR & 0.634 & 1 & 50 & $0.432-0.775$ & NA & NA & NA \\
\hline & $\mathrm{VO}_{2}$ & 0.710 & 1 & 50 & $0.538-0.825$ & NA & NA & NA \\
\hline \multirow[t]{2}{*}{ EP-RPE } & HR & $0.916^{\mathrm{a}}$ & 2 & 29 & $0.820-0.962$ & $<0.001$ & 0.7532 & $0.0 \%(0.3854)$ \\
\hline & $\mathrm{VO}_{2}$ & $0.906^{\mathrm{a}}$ & 2 & 29 & $0.798-0.957$ & $<0.001$ & 0.6074 & $0.0 \%(0.4358)$ \\
\hline \multirow[t]{2}{*}{ MDT } & $\mathrm{HR}$ & $0.866^{\mathrm{a}}$ & 2 & 29 & $0.721-0.939$ & $<0.001$ & 0.08211 & $0.0 \%(0.7745)$ \\
\hline & $\mathrm{VO}_{2}$ & $0.870^{\mathrm{a}}$ & 2 & 29 & $0.728-0.940$ & $<0.001$ & 0.0000 & $0.0 \%(1.0)$ \\
\hline
\end{tabular}

k: number of articles; n: sample size; Q: heterogeneity index; I2: inconsistency index; NA: no meta-analysis done; a: using the fixed effects model; b: using the random effects model; 15-point Rate of Perceived Exertion (RPE 6-20); Children's Effort Rating Table (CERT); children's OMNI scale of perceived exertion; 15-point Rate Of Perceived Exertion-Children (RPE-C); Pictorial Children's Effort Rating Table (PCERT); Cart and Load Effort Rating (CALER); Children's Rating of Perceived Exertion Scale (C-RPES); Borg ratings of perceived exertion scale (CR-10); Eston-Parfitt curvilinear Ratings of Perceived Exertion (EP-RPE); marble dropping task (MDT); HR: heart rate; VO2: oxygen uptake; VE: minute ventilation; VCO2/VO2: respiratory ratio; VE/VO2: ventilatory equivalent ratio for oxygen. 
scales that have been specifically adapted to children seem to have a better performance than those that have not been adapted.
Notwithstanding, further studies with better methodological quality should be conducted in order to confirm these conclusions.

TABLE 3. Criterion-related validity of perceived exertion measurement

\begin{tabular}{|c|c|c|c|c|c|c|c|}
\hline Covariates & Average $r$ & $\mathbf{k}$ & $\mathbf{n}$ & $95 \%$ CI & $p$ & Q & $\mathrm{I}^{2}(p$-value $)$ \\
\hline \multicolumn{8}{|l|}{ Sex } \\
\hline Boy & $0.847^{\mathrm{b}}$ & 14 & 370 & $0.780-0.895$ & $<0.001$ & 75.8810 & $73.64 \%(<0.0001)$ \\
\hline Girl & $0.851^{\mathrm{b}}$ & 13 & 391 & $0.774-0.903$ & $<0.001$ & 117.9435 & $83.04 \%(<0.0001)$ \\
\hline \multicolumn{8}{|l|}{ *Age } \\
\hline$<7$ years old & $0.821^{\mathrm{b}}$ & 2 & 41 & $0.450-0.950$ & 0.001 & 7.5838 & $73.63 \%(0.0226)$ \\
\hline 8-12 years old & $0.863^{\mathrm{b}}$ & 18 & 1040 & 0.803-0.906 & $<0.001$ & 285.2875 & $90.89 \%(<0.0001)$ \\
\hline $13-15$ years old & $0.937^{b}$ & 4 & 131 & $0.828-0.978$ & $<0.001$ & 39.9800 & $87.49 \%(<0.0001)$ \\
\hline$>15$ years old & $0.723^{\mathrm{b}}$ & 3 & 81 & $0.493-0.858$ & $<0.001$ & 8.6094 & $76.77 \%(0.0135)$ \\
\hline \multicolumn{8}{|l|}{ Exercise test } \\
\hline Continuous progressive & $0.875^{\mathrm{b}}$ & 21 & 1271 & $0.812-0.918$ & $<0.001$ & 414.6569 & $93.01 \%(<0.0001)$ \\
\hline Intermittent progressive & $0.760^{\mathrm{b}}$ & 4 & 147 & $0.602-0.860$ & $<0.001$ & 37.7057 & $81.44 \%(<0.0001)$ \\
\hline \multicolumn{8}{|l|}{ Exercise modality } \\
\hline Bike & $0.865^{\mathrm{b}}$ & 13 & 831 & $0.784-0.917$ & $<0.001$ & 273.6051 & $92.69 \%(<0.0001)$ \\
\hline Run & $0.807^{b}$ & 9 & 387 & $0.722-0.867$ & $<0.001$ & 66.4815 & $80.45 \%(<0.0001)$ \\
\hline Step & $0.907^{b}$ & 3 & 200 & $0.704-0.973$ & $<0.001$ & 140.7281 & $95.74 \%(<0.0001)$ \\
\hline \multicolumn{8}{|l|}{ Assessment paradigm } \\
\hline Estimation & $0.868^{\mathrm{b}}$ & 23 & 1348 & $0.815-0.906$ & $<0.001$ & 452.3205 & $91.60 \%(<0.0001)$ \\
\hline Production & $0.550^{\mathrm{a}}$ & 2 & 86 & $0.427-0.653$ & $<0.001$ & 2.3499 & $14.89 \%(0.3088)$ \\
\hline \multicolumn{8}{|l|}{ Other reference criteria } \\
\hline Workload & $0.811^{\mathrm{b}}$ & 7 & 303 & $0.724-0.873$ & $<0.001$ & 43.0231 & $75.01 \%(<0.0001)$ \\
\hline RR & $0.695^{\mathrm{b}}$ & 4 & 218 & $0.437-0.847$ & $<0.001$ & 40.4234 & $90.10 \%(<0.0001)$ \\
\hline VE & $0.828^{b}$ & 7 & 297 & $0.698-0.906$ & $<0.001$ & 98.2091 & $89.82 \%(<0.0001)$ \\
\hline $\mathrm{VCO}_{2} / \mathrm{VO}_{2}$ & $0.732^{\mathrm{b}}$ & 3 & 155 & $0.556-0.845$ & $<0.001$ & 14.2162 & $78.90 \%(0.0026)$ \\
\hline $\mathrm{VE} / \mathrm{VO}_{2}$ & 0.260 & 2 & 120 & $-0.0103-0.495$ & 0.059 & 6.6834 & $70.08 \%(0.0354)$ \\
\hline
\end{tabular}

k: number of articles; n: sample size; Q: heterogeneity index; I2: inconsistency index; NA: no meta-analysis done; a: using the fixed effects model; b: using the random effects model; 15-point Rate of Perceived Exertion (RPE 6-20); Children's Effort Rating Table (CERT); children's OMNI scale of perceived exertion; 15-point Rate Of Perceived Exertion-Children (RPE-C); Pictorial Children's Effort Rating Table (PCERT); Cart and Load Effort Rating (CALER); Children's Rating of Perceived Exertion Scale (C-RPES); Borg ratings of perceived exertion scale (CR-10); Eston-Parfitt curvilinear Ratings of Perceived Exertion (EP-RPE); marble dropping task (MDT); HR: heart rate; $\mathrm{VO}_{2}$ : oxygen uptake; VE: minute ventilation; $\mathrm{VCO}_{2} / \mathrm{VO}_{2}$ : respiratory ratio; $\mathrm{VE} / \mathrm{VO}_{2}$ : ventilatory equivalent ratio for oxygen.

\section{REFERENCES}

1. Garber CE, Blissmer B, Deschenes MR, Franklin BA, et al. AmericanCollegeofSports Medicinepositionstand.Quantity and quality of exercise for developing and maintaining cardiorespiratory, musculoskeletal, and neuromotor fitnessin apparently healthy adults: guidance for prescribing exercise. Med Sci Sports Exerc 2011;43(7):1334-59.

2. Groslambert A, Mahon AD. Perceived exertion: influence of age and cognitive development. Sports Med 2006; 36(11):911-28.

3. Chen MJ, Fan X, Moe ST. Criterion-related validity of the Borg ratings of perceived exertion scale in healthy individuals: a meta-analysis. J Sports Sci 2002;20(11):873-99.

4. Eston RG, Williams JG. Exercise intensity and perceived exertion in adolescent boys. Br J Sports Med 1986;20(1):27-30.

5. Gillach MC, Sallis JF, Buono MJ, Patterson P, et al. The relationship between perceived exertion and heart rate in children and adults. Pediatr Exerc Sci 1989;1(4):360-8.

6. Lamb KL. Children's ratings of effort during cycle ergometry: an examination of the validity of two effort rating scales. Pediatr Exerc Sci 1995;7(4):407-21.

7. Lamb KL. Exercise regulation during cycle ergometry using the Children's Effort Rating Table (CERT) and Rating of Perceived Exertion (RPE) scales. Pediatr Exerc Sci1996;8(4):337-50.

8. Moher D, Liberati A, Tetzlaff J, Altman DG. Preferred reporting items for systematic reviews and meta-analyses: the PRISMA statement. Int J Surg 2010;8(5):336-41.

9. Mokkink LB, Terwee CB, Patrick DL, Alonso J, et al. The COSMIN study reached international consensus on taxonomy, terminology, and definitions of measurement properties for health-related patient-reported outcomes. J Clin Epidemiol 2010;63(7):737-45.

10. Sterne JA, Sutton AJ, Ioannidis JP, Terrin N, et al. Recommendations for examining and interpreting funnel plot asymmetry in meta-analyses of randomised controlled trials. BMJ 2011;343:d4002.

11. Balasekaran G, Loh MK, Govindaswamy VV, Cai SJ. Omni 
Scale Perceived Exertion responses in obese and normal weight male adolescents during cycle exercise. J Sports Med Phys Fitness 2014;54(2):186-96.

12. Eakin BL, Finta KM, Serwer GA, Beekman RH. Perceived exertion and exercise intensity in children with or without structural heart defects. J Pediatr 1992;120(1):90-3.

13. Groslambert A, Hintzy F, Hoffman MD, Dugué B, et al. Validation of a rating scale of perceived exertion in young children. Int J Sports Med 2001;22(2):116-9.

14. Leung ML, Chung PK, Leung RW. An assessment of the validity and reliability of two perceived exertion rating scales among Hong Kong children. Percept Mot Skills 2002;95(3 Pt 2):1047-62.

15. Pfeiffer KA, Pivarnik JM, Womack CJ, Reeves MJ, et al. Reliability and validity of the Borg and OMNI rating of perceived exertion scales in adolescent girls. Med Sci Sports Exerc 2002;34(12):2057-61.

16. Eston RG, Lamb KL, Bain A, Williams AM, et al. Validity of a perceived exertion scale for children: a pilot study. Percept Mot Skills 1994;78(2):691-7.

17. Williams JG, Eston R, Furlong B.CERT: a perceived exertion scale for young children. Percept Mot Skills 1994;79(3 Pt 2):1451-8.

18. Leung R, Pak-Kwong C, BowerG. Validation of a translated children perceived exertion rating scale. Int J Fit 2008;4(2):4956.

19. Balasekaran G, Loh MK, Govindaswamy VV, Robertson RJ. OMNI Scale of Perceived Exertion: mixed gender and race validation for Singapore children during cycle exercise. Eur J Appl Physiol 2012;112(10):3533-46.

20. Barkley JE, Roemmich JN. Validity of the CALER and OMNI-bike ratings of perceived exertion. Med Sci Sports Exerc 2008;40(4):760-6.

21. Robertson RJ, Goss FL, Boer NF, Peoples JA, etal.Children's OMNI scale of perceived exertion: mixed gender and race validation. Med Sci Sports Exerc 2000;32(2):452-8.

22. Robertson RJ, Goss FL, Aaron DJ, Tessmer KA, et al. Observation of perceived exertion in children using the OMNI pictorial scale. Med Sci Sports Exerc 2006;38(1):158-66.

23. Roemmich JN, Barkley JE, Epstein LH, Lobarinas CL, et al. Validity of PCERT and OMNI walk/run ratings of perceived exertion. Med Sci Sports Exerc 2006;38(5):1014-9.
24. Suminski RR, Robertson RJ, Goss FL, Olvera N. Validation of the Omni Scale of Perceived Exertion in a sample of Spanish-speaking youth from the USA. Percept Mot Skills 2008;107(1):181-8.

25. Utter AC, Robertson RJ, Nieman DC, Kang J. Children's OMNI Scale of Perceived Exertion: walking/running evaluation. Med Sci Sports Exerc 2002;34(1):139-44.

26. Robertson RJ, Goss FL, Andreacci JL, Dubé JJ, et al. Validation of the children's OMNI RPE scale for stepping exercise. Med Sci Sports Exerc 2005;37(2):290-8.

27. Marinov B, MandadjievaS, Kostianev S. Pictorial and verbal category-ratio scales for effort estimation in children. Child Care Health Dev 2008;34(1):35-43.

28. Yelling M, Lamb KL, Swaine IL. Validity of a pictorial perceived exertion scale for effort estimation and effort production during stepping exercise in adolescent children. EurPhyEduc Rev 2002;8(2):157-75.

29. Cassady SL, Kaufman BA, Kelly CE, Eisenmann SC, et al. Validity of a New Perceived Exertion Scale for Children. Cardiopulm Phys Ther J 1998;9(1):3-8.

30. Eston RG, Lambrick DM, Rowlands AV. The perceptual response to exercise of progressively increasing intensity in children aged 7-8 years: validation of a pictorial curvilinear ratings of perceived exertion scale. Psychophysiology 2009;46(4):843-51.

31. Lambrick DM, Rowlands AV, Eston RG. The perceptual response to treadmill exercise using the Eston-Parfitt scale and marble dropping task, in children age 7 to 8 years. Pediatr Exerc Sci 2011;23(1):36-48.

32. Groslambert A, Monnier Benoit P, Grange CC, Rouillon JD. Self-regulated running using perceived exertion in children. J Sports Med Phys Fitness 2005;45(1):20-5.

33. Parfitt G, Shepherd P, Eston RG. Reliability of effort production using the children's CALER and BABE perceived exertion scales. J Exerc Sci Fit 2007;5(1):49-55.

34. Rice KR, Gammon C, Pfieffer K, Trost SG. Age related differences in the validity of the OMNI perceived exertion scale during lifestyle activities. Pediatr Exerc Sci 2015;27(1):95-101.

35. Ward DS, Jackman JD, Galiano FJ. Exercise intensity reproduction: children versus adults. Pediatr Exerc Sci 1991;3(3):209-18. 


\section{Annex. Funnel plot}

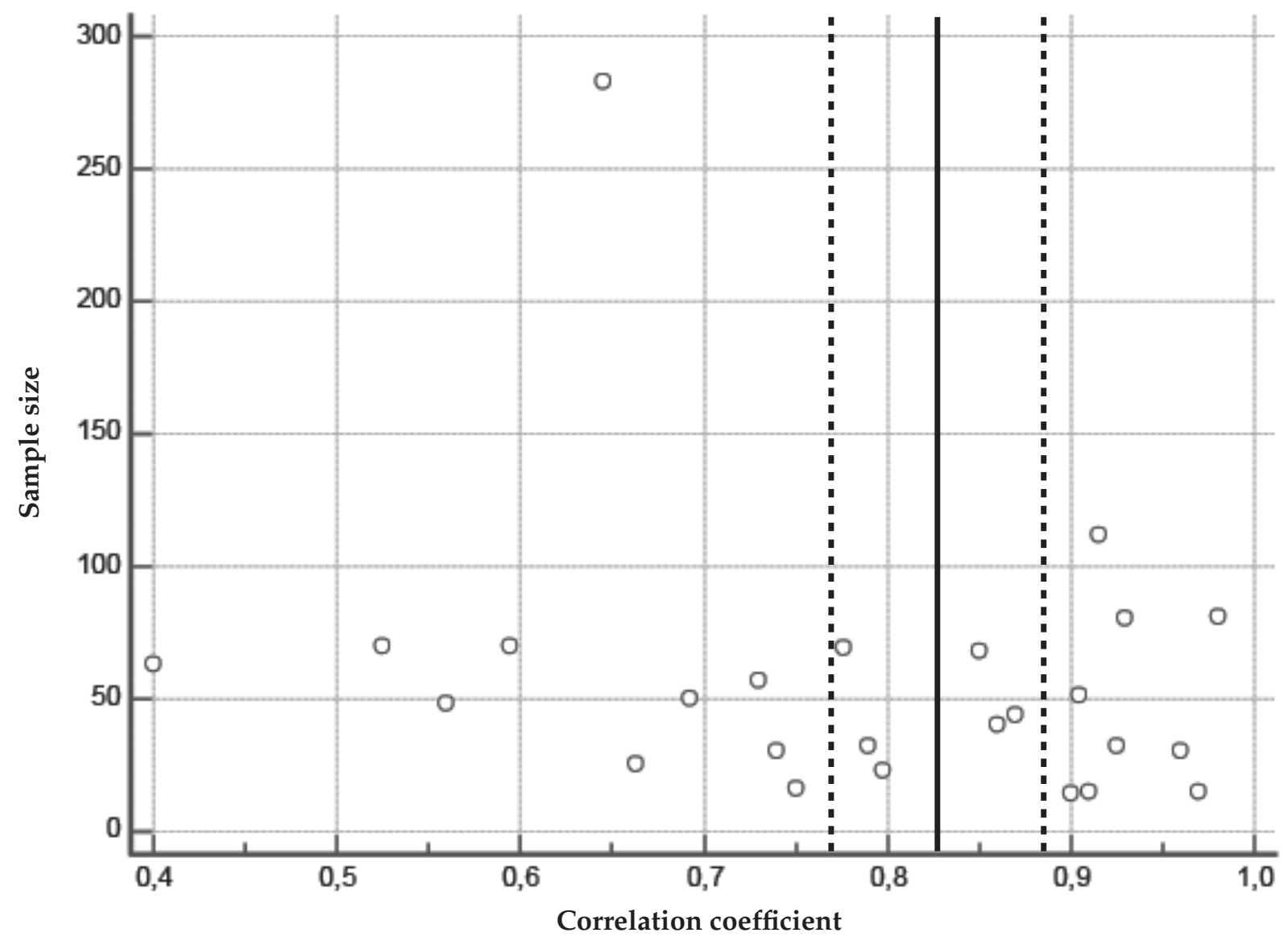

The solid line shows the weighted mean; the dotted line shows the $95 \%$ confidence interval. 